\title{
Evaluation and Comparison of Stress Status between Hypertensive and Normotensive Subjects
}

\author{
Radhika $\mathbf{P}^{1}$, Angel Jose ${ }^{2}$ \\ ${ }^{1}$ Tutor, Department of Physiology, Vydehi Institute of Medical Science \& Research Centre, Bangalore \\ ${ }^{2}$ Associate Professor, Department of Physiology, Little Flower Institute of Medical Science and Research \\ Centre, Kerala
}

Corresponding Author: Radhika P

\begin{abstract}
Hypertension is a prevalent life style disease that causes cardiovascular diseases associated mortality worldwide. Being a devastating endemic, hypertension require special emphasis to be studied for its complications and consequences. Existing literatures provide robust evidences of the disastrous effects of hypertension on psychological stress separately, but there are least evidences comparing the same between hypertensive and normotensive adults. This study mainly concentrates on the effect of hypertension on stress levels and its comparison between hypertensive and normotensive individuals.

Objective: To identify the differences of stress status among hypertensive and normotensive individuals.

Methods: A CASE and a CONTROL group each constituting with a sample of 44 subjects between the age group 25-65 years were recruited in the study. The stress status of the study group was assessed by the Perceived Stress Scale (PSS). Data were statistically analyzed using SPSS (Version 20.0). Descriptive statistics were presented as frequencies, percentages and mean \pm S.D. Statistical differences between the stress status of case and control groups were conducted by Independent Sample T-test.
\end{abstract}

Results: Majority (54.5\%) of the hypertensive patients belonged to the age group of 56-65 years. The average Perceived Stress Scale (PSS) Scores of the case group were 26.68 \pm 6.03 and that of the control group were $10.43 \pm 6.57$. The differences between the Average PSS scores of the case and control groups were found to be highly statistically significant (P-0.00).

Conclusions: Hypertensive cases recruited for the study had moderate and high levels of stress when compared to the normotensive controls of the same age- group (25-65years).

Keywords: Hypertension; Normotension; Stress Status; Perceived Stress Scale

\section{INTRODUCTION}

Hypertension is a very common and most prevalent public health challenge in both economically developing and developed countries of the world. Hypertension can be defined as a systolic BP level $\geq 140 \mathrm{mmHg}$ and/or a diastolic BP level $\geq 90 \mathrm{mmHg}$. The number of hypertensive adults will reach 1.5 billion which is approximately $30 \%$ of the world population by the year $2025^{[1]}$. It is one of the inevitable risk factors of cardiovascular diseases related mortality. Poorly controlled
Blood Pressure (BP) remains to be a strong reason of cardiovascular morbidity and mortality worldwide.

Psychological stress is an important risk factor for hypertension and there is some evidence on the association between elevated BP and psychological stress. Moreover, some studies mentioned that associations of psychological stress and elevated BP were different by gender ${ }^{[2]}$, That is, it contributes to greater risk for hypertension in women than in men. The impact of stress on the development of high 
BP also involves a sympathetic nervous system response, in which the release of catechol-amines causes increased Heart Rate, Cardiac Output and Blood Pressure. ${ }^{[3]}$

\section{MATERIALS AND METHODS}

PARTICIPANTS: Normotensive and hypertensive individuals within the age group range 25-65.

\section{SAMPLE SIZE:}

CASE: 44 subjects already diagnosed with hypertension within the specified age group

CONTROL: 44 normotensive subjects within the specified age group.

SAMPLING TECHNIQUE: Stratified Random Sampling- The heterogeneous population was divided into 2 strata: Hypertensive and Normotensive. The samples were then recruited randomly from these strata considering the inclusion and exclusion criteria.

\section{INCLUSION CRITERIA:}

- Male and female patients between the age group 25 and 65 already diagnosed with hypertension.

- Male and female normotensive participants between the age group range 25-65.

- Willing participants.

\section{EXCLUSION CRITERIA:}

- Patients suffering from any major diseases like cancer, chronic infectious diseases etc.

- Patients undergoing any therapy or treatment.

- Hypotensive individuals

- Normotensive people suffering from any other serious medical conditions like renal tubular defects, hormonal excess or insufficiency etc. that can affect Blood Pressure.

STUDY DESIGN: Descriptive and comparative Case- Control study

STUDY SETTING: The study was conducted in the patients and staffs of Little Flower Hospital, Angamaly, Ernakulam
District, Kerala who visited the OPD for weekly checkup.

ETHICAL CONSIDERATIONS: The study was approved by the Ethical Committee of Little Flower Institute of Medical Science and Research (LIMSAR), Angamaly, no: EC/08/2018 Permission was also obtained from the OPD In - Charge to collect data from the patients.

STUDY DURATION: A total of six months duration between December 2018 and June 2019 was taken for completing the study.

DATA COLLECTION: A set of 2 groups; a CASE and a CONTROL each constituting with a sample of 44 subjects between the age group 25-65 years of age were recruited in the study. The case group of 44 hypertensive patients were randomly chosen from the Out Patient Department of LF Hospital Angamaly and the control group of 44 normotensive individuals were chosen randomly from the staffs of various departments of the same hospital.

The subjects in the study were within the age group 25-65 and were recruited as 2 groups:

- Study group - Consisting 44 individuals with a previous history of hypertension or with an already diagnosed high BP.

- Control group - Consisting of 44 individuals within a normal blood pressure range. (Normotensive).

- Data were collected from the patients only after getting written informed consent.

\section{Assessment of stress status}

Using Perceived Stress Scale (PSS): PSS is a most widely used classical stress assessment scale. Originally, it is a 14-item scale and assess the perception level of stress by allowing the respondent to rate the frequency of his/her feelings and thoughts related to certain stress full or other events that occurred during the previous month. ${ }^{[4]}$ There are 2 product short- forms of the originally developed PSS-14: PSS- 10 and PSS-4 and PSS-10 was used in this study. High PSS scores have been associated with 
elevated biomarkers of stress, like cortisol. $[5,6]$ Six of the items were negative $(1,2,3$, $6,9,10)$ and the rest four as positive $(4,5$, 7, 8), representing 2 factors, perceived helplessness and self-efficacy, respectively. Each question was rated on a 5-point Likerttype scale ( 0 - never to 4 - very often). Total scores are calculated after reversing the scores of the four positive items and then adding up all scores. Total scores for PSS10 ranges between 0 - 40. A highest score indicates greatest stress. ${ }^{[4]}$

STATISTICAL ANALYSIS: Data were analyzed in the Statistical Package for
Social Sciences (20.0). Descriptive statistics of the data were presented as frequencies, percentages and mean \pm SD. Comparison of means between the cases and controls were done using the Independent Sample T- test.

\section{RESULTS}

In the case- control observational study, a total of 88 subjects of which 44 cases with hypertension and 44 controls with normotension were incorporated for the analysis. Both descriptive statistics and comparison of means were conducted, and results were obtained.

\section{SECTION 1: BASELINE CHARACTERISTICS OF THE DATA}

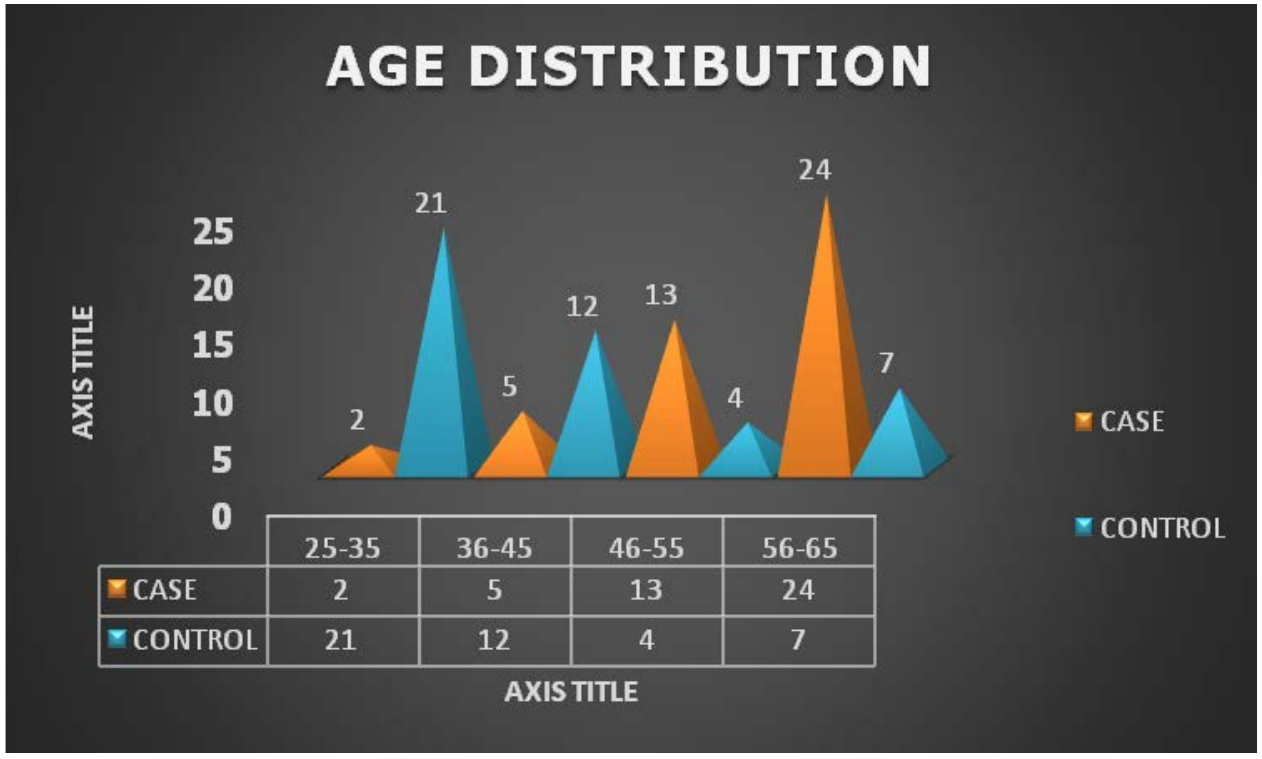

Graph 1: Distribution of age among the study population

Graph 1 shows the age distribution of cases and controls in the study population. The mean age of the case group was distributed as $55.11 \pm 8.83$ and that of control group were distributed as 39.11 \pm 11.81 . Majority (54.5\%) of the hypertensive patients belonged to the age group of 56-65 years and in that of control group majority (47.7\%) of the normotensive individuals belongs to the age group of 2535 years. Minor population (4.5\%) of hypertensive cases belongs to the age group of 25-35 years and in that of control group minority (9.1\%) of the normotensive individuals belong to the age group 46-55 years of age. This shows that there are no notable incidence and prevalence of hypertension among a wide range of age groups in this study population.

Graph 2 \& 3 shows the gender distribution of the study population. Graph 2 shows that $54.5 \%$ of the case group were males and $45.5 \%$ were females. Graph 3 shows that in the control group majority (63.6\%) were females and only $36.4 \%$ were males. 
CASE GROUP

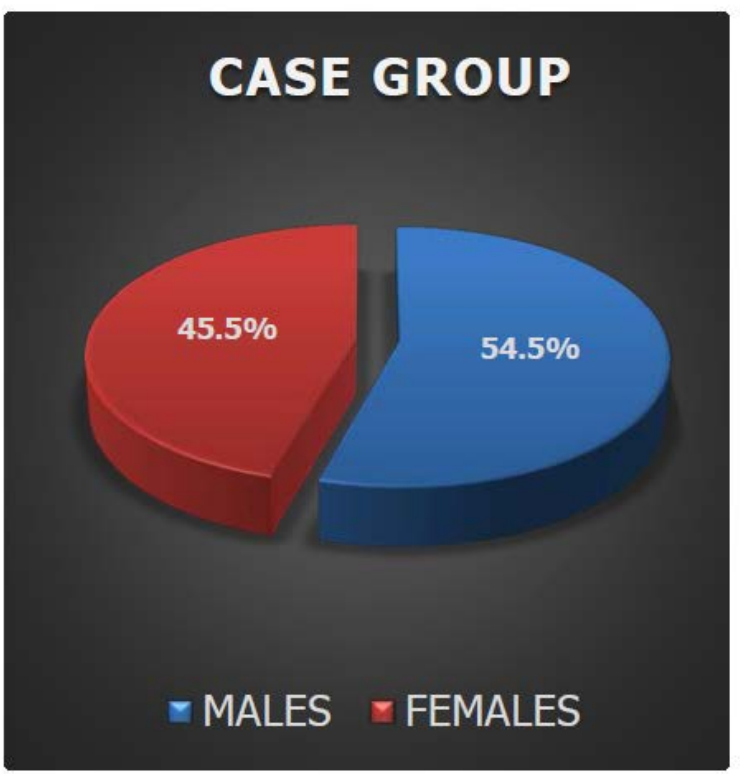

Graph 2 \& 3: Gender distribution of the study population

\section{BMI DISTRIBUTION}

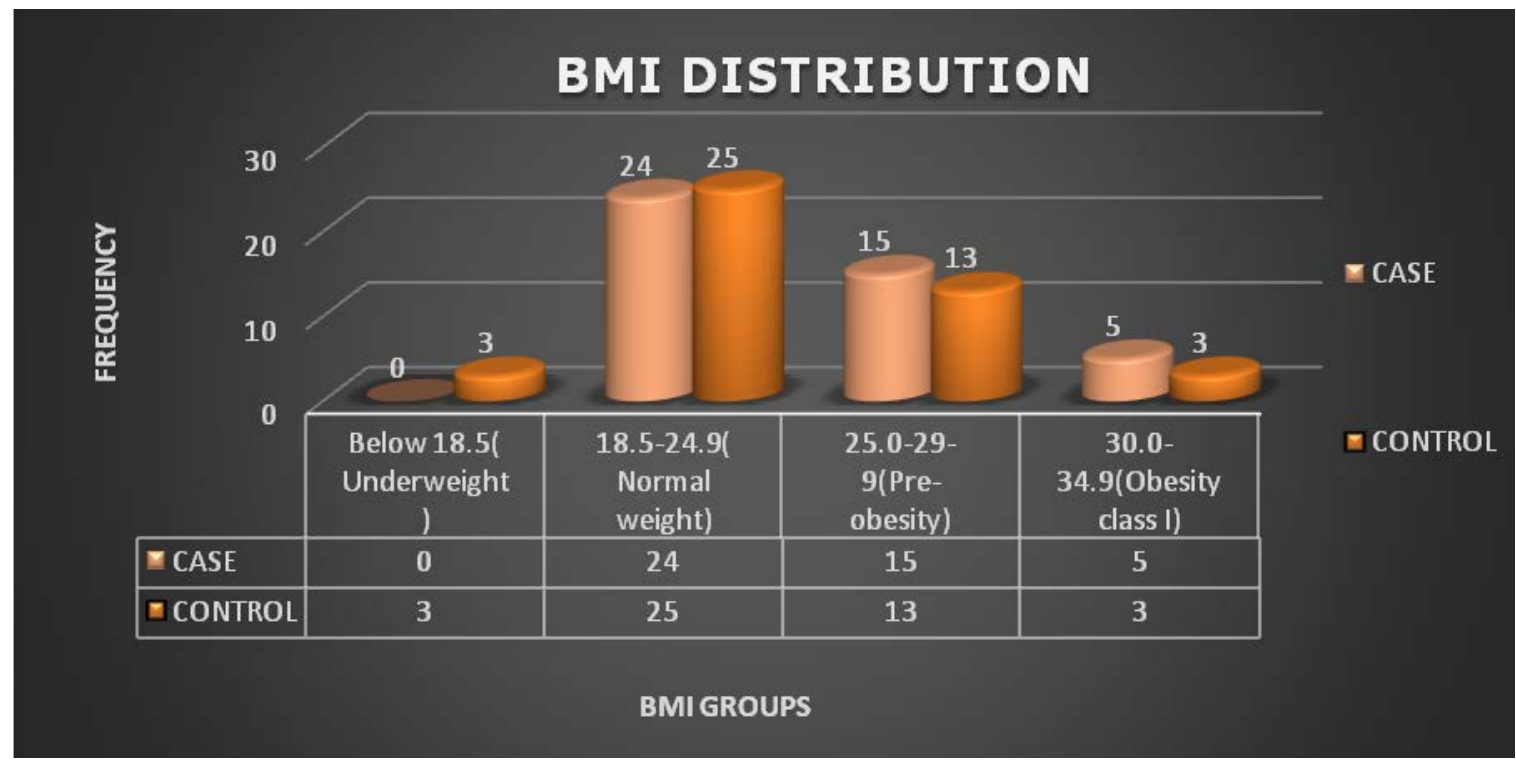

BMI GROUPS

\section{CONTROL GROUP}

$36.4 \%$
$63.6 \%$

Graph 4: BMI distribution of the study population

Graph 4 shows the BMI distribution of the population as per the WHO standards of BMI and indicates that almost half of the cases (54.5\%) and controls (56.8\%) come under the category of normal weight. About $34.1 \%$ of the cases are pre-obese in nature and about $11.4 \%$ are obese in nature which attributes to the fact that obesity is a risk factor for hypertension. About 29.5\% of the controls are pre-obese and $6.8 \%$ are obese and about $6.8 \%$ of them are underweight in nature.

Table 1: Distribution of Resting Systolic BP (SBP) in the Study population

\begin{tabular}{|c|c|c|c|c|c|}
\hline \multirow{3}{*}{$\begin{array}{l}\text { SBP RANGE (IN mmHg) * } \\
\text { MEAN } \pm \text { SD }\end{array}$} & \multicolumn{2}{|c|}{ CASE GROUP } & \multirow{3}{*}{$\begin{array}{l}\text { SBP RANGE } \\
\text { (IN mmHg)* } \\
\text { MEAN } \pm \text { SD }\end{array}$} & \multicolumn{2}{|c|}{ CONTROL GROUP } \\
\hline & \multicolumn{2}{|c|}{$129.09 \pm 21.43$} & & \multicolumn{2}{|c|}{$113.41 \pm 11.19$} \\
\hline & $\mathbf{F}$ & $\%$ & & $\mathbf{F}$ & $\%$ \\
\hline OPTIMAL $(<120)$ & 12 & 27.3 & OPTIMAL $(<120)$ & 26 & 59.1 \\
\hline NORMAL (120-129) & 11 & 25.0 & NORMAL (120-129) & 9 & 20.5 \\
\hline HIGH NORMAL (130-139) & 7 & 15.9 & HIGH NORMAL (130-139) & 9 & 20.5 \\
\hline GRADE- 1 HYPERTENSION (140-159) & 8 & 18.2 & GRADE 1 (140-159) & 0 & 0 \\
\hline GRADE-2 (160-179) & 4 & 9.1 & GRADE-2 (160-179) & 0 & 0 \\
\hline GRADE- $3(\geq 180)$ & 2 & 4.5 & GRADE- $3(\geq 180)$ & 0 & 0 \\
\hline TOTAL & 44 & 100 & TOTAL & 44 & 100 \\
\hline
\end{tabular}


Table 1 shows the distribution of resting systolic BP among the cases and controls. According to the ESC/ESH guidelines, among the case group about $27.3 \%$ had an optimal range of SBP, about $25 \%$ had normal range of SBP and about $15.9 \%$ had high normal SBP possibly attained through medication. Remaining $18.2 \%, 9.1 \%$ and $4.5 \%$ had grade- 1,2 and 3 hypertensions respectively indicating the prevalence of systolic pre- hypertension and hypertension in most of the cases. Among the control group, $59.1 \%$ of the samples had an optimal resting systolic BP and the remaining $20.5 \%$ had normal and high normal SBP, with very few of the samples presenting with pre-systolic hypertension susceptive of anticipatory hypertension or due to any other reasons.

Table 2: Distribution of Resting Diastolic BP (DBP) in the study population

\begin{tabular}{|c|c|c|c|c|c|}
\hline \multirow{3}{*}{$\begin{array}{l}\text { DBP RANGE (IN mmHg) } \\
\text { MEAN } \pm \text { SD }\end{array}$} & \multicolumn{2}{|c|}{ CASE GROUP } & \multirow{3}{*}{$\begin{array}{l}\text { DBP RANGE } \\
\text { (IN mmHg) } \\
\text { MEAN } \pm \text { SD }\end{array}$} & \multicolumn{2}{|c|}{ CONTROL GROUP } \\
\hline & \multicolumn{2}{|c|}{$82.27 \pm 11.78$} & & \multicolumn{2}{|c|}{$73.07 \pm 7.64$} \\
\hline & $\mathbf{F}$ & $\%$ & & $\mathbf{F}$ & $\%$ \\
\hline OPTIMAL $(<80)$ & 15 & 34.1 & OPTIMAL $(<80)$ & 27 & 61.4 \\
\hline NORMAL (80-84) & 12 & 27.3 & NORMAL (80-84) & 15 & 34.1 \\
\hline GRADE 1(85-89) & 11 & 25.0 & GRADE 1(85-89) & 2 & 4.5 \\
\hline GRADE 2(90-99) & 5 & 11.4 & GRADE 2(90-99) & 0 & 011.4 \\
\hline GRADE $3(\geq 110)$ & 1 & 2.3 & GRADE $3(\geq 110)$ & 0 & 0 \\
\hline Total & 44 & 100.0 & Total & 44 & 100.0 \\
\hline
\end{tabular}

Table 2 shows the distribution of resting DBP among the cases and controls. About $34.1 \%$ and $27.3 \%$ of the cases had an optimal and normal DBP respectively probably attained due to medication. About $25 \%, 11.4 \%$ and $2.3 \%$ had grade- 1 , grade -2 and grade- 3 diastolic hypertension respectively indicating the prevalence of both diastolic pre- hypertension and hypertension in the resting state. Among the controls majority $61.4 \%$ had optimal DBP, $34.1 \%$ had a normal DBP and only a few (4.5\%) had grade - 1 diastolic hypertension possibly due to some other reasons.

\section{SECTION 2: STRESS STATUS}

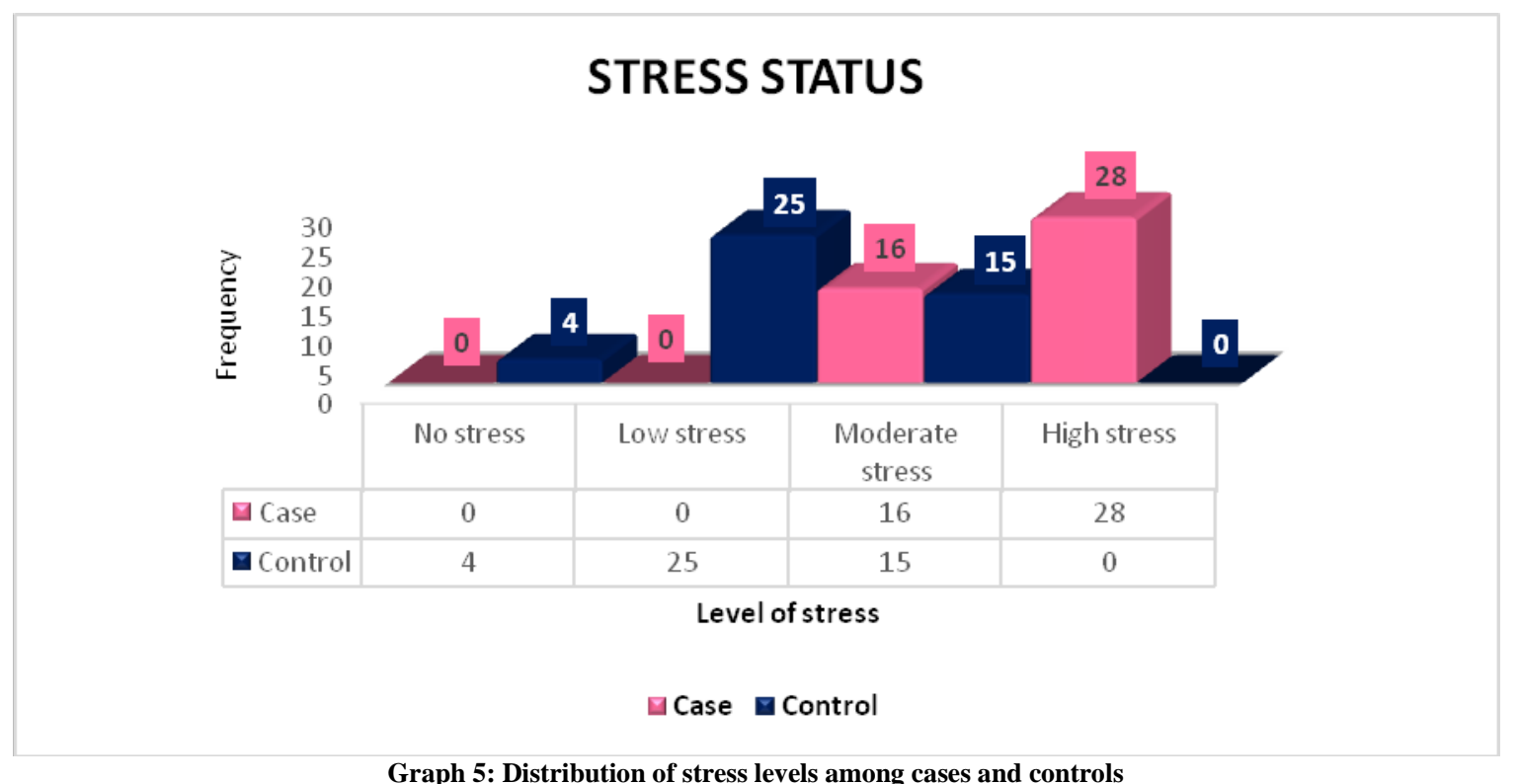

Graph 5 shows the distribution of level of stress among the cases and controls.
The average Perceived Stress Scale (PSS)

Scores of the case group were $26.68 \pm 6.03$ 
and that of the control group were $10.43 \pm 6.57$. Among the case group majority (63.6\%) had high levels of stress and the remaining (36.4\%) had moderate stress, none of them presented with "no stress" and "low stress". Among the controls, about $56.8 \%$ had low stress, $34.1 \%$ had moderate stress, 9.1\% were with no stress and none of them had a high level of stress.

Table 3: Comparison of stress status among cases and controls

\begin{tabular}{|l|l|l|l|l|l|}
\hline GROUPS & N & MEAN (Average PSS Scores) & STANDARD DEVIATION & t- VALUE & P VALUE \\
\hline Hypertensive & 44 & 26.68 & 6.03 & 12.082 & 0.000 \\
\hline Normotensive & 44 & 10.43 & 6.57 & & \\
\hline
\end{tabular}

Table 3 shows the distribution of mean PSS scores among hypertensive cases and normotensive controls. The mean PSS score of the case group was 26.68 and that of the controls were 10.43 depicting a high level of stress among hypertensive patients. The differences between the Average PSS scores of the case and control groups were found to be highly significant statistically $(\mathrm{P}=0.00)$. This explains the fact that hypertensive individuals have very high stress compared to that of the normotensive group.

\section{DISCUSSION}

Hypertension is a life-threatening public health challenge irrespective of age groups and is associated with several complications mainly affecting cardiovascular functions, sleeping patterns and quality, autonomic nervous system functions, level of stress, renal functions and much more. Existing evidences focused on the impact of hypertension on sleep quality, stress status and autonomic function as separate parameters and no comparative studies were conducted yet to analyze the possible differences and to arrive at accurate conclusions. The present study aims to understand the effects of hypertension on quality of sleep, stress and autonomic function in hypertensive subjects and to compare those with normotensive subjects. Also, screening was conducted to identify the prevalence of sleep disorders among hypertensive subjects and to understand the incidence and prevalence of hypertension among a wide range of age group.

Stress is considered as a
determinant of

hypertension and they are known to be related linearly. ${ }^{[10]}$ In an ISIAH rat strain study on the genes related to stress- induced hypertension, the possible reasons for development of persistent stress- induced hypertension was clearly elucidated which indicates that stress is a major causative factor of hypertension. ${ }^{[11]}$

As per the results obtained in this study there is a statistically significant difference between the stress status among hypertensive and normotensive subjects. Out of the total hypertensive cases, majority of them were found to be suffering from high levels of stress and the minor group had moderate levels of stress. Among the normotensive controls, majority of the population had no stress, and a few suffered from low and moderate levels of stress. As per this self- reported data, it can be inferred that hypertensive patients have significant stress states and the stressors predominantly affects sympathetic activity since stress hormones activate sympathetic stimulation. This study puts- forth further investigations in quantitative or invasive analysis regarding the aspects of stress status as the data collected were self- reported rather being analyzed based on humoral changes associated with stress. The study was conducted in a small sample group and employing more number of samples in the future research may prove the facts and relationships in a better possible way.

\section{ACKNOWLEDGEMENTS}

I would like to extend my intense gratitude to Ms. Mary Shalu Jose, Associate Professor, Department of Physiology, LIMSAR, Angamaly who had helped me 
throughout in accomplishing this work. Also I'm deeply grateful to Dr. J.K Mukkadan, Research Director, LFMRC, and Angamaly for his ever ending support and guidance

\section{Conflict of Interest: None}

\section{Source of Funding: None}

\section{Ethical Approval: Approved}

\section{REFERENCES}

1. Kearney PM, Whelton M, Reynolds K, Muntner P, Whelton PK, He J Global burden of hypertension: analysis of worldwide data.2005. Lancet 365: 217-223.

2. $\mathrm{Hu}, \mathrm{Bo}$ et al. "Effects of psychological stress on hypertension in middle-aged Chinese: a cross-sectional study." PloS one vol. 10,6 e0129163. 4 Jun. 2015.

3. Tanya M. Spruill, Chronic Psychosocial Stress and Hypertension, Curr Hypertens Rep. 2010 Feb; 12(1): 10-16.

4. Andreou, E., Alexopoulos, E. C., Lionis, C., Varvogli, L., Gnardellis, C., Chrousos, G. P., \& Darviri, C. (2011). Perceived Stress Scale: reliability and validity study in Greece. International journal of environmental research and public health, 8(8), 3287-3298.

5. Malarkey WB, Pearl DK, Demers LM, Kiecolt-Glaser JK, Glaser R. Influence of academic stress and season on 24-hour mean concentrations of ACTH, cortisol, and beta-endorphin. Psychoneuroendocrinology. 1995;20:499-508.

6. Van Eck MM, Nicolson NA. Perceived stress and salivary cortisol in daily life. Ann. Behav. Med. 1994;16:221-227.

7. H.K Chopra, C.Venkata S.Ram. Recent guidelines for hypertension, A Clarion call for BP control in India. Circulation Research.28 March 2019:124:984-986
8. Williams B, Mancia G, Spiering W, et al.; ESC Scientific Document Group. 2018 ESC/ESH guidelines for the management of arterial hypertension.Eur Heart J. 2018; 39:3021-3104.

9. Whelton PK, Carey RM, Aronow WS, et al.. 2017

ACC/AHA/AAPA/ABC/ACPM/AGS/APh A/ASH/ASPC/NMA/PCNA guideline for the prevention, detection, evaluation, and management of high blood pressure in adults: executive summary: a report of the American College of Cardiology/American Heart Association task force on clinical practice guidelines. J Am Coll Cardiol. 2018; 71:2199-2269.

10. Kulkarni $S^{1}$, O'Farrell I, Erasi M, Kochar MS, Stress and hypertension. WMJ. 1998 Dec;97(11):34-8.

11. Redina, O.E., Markel, A.L. Stress, Genes, and Hypertension. Contribution of the ISIAH Rat Strain Study. Curr Hypertens Rep 20, 66 (2018) doi:10.1007/s11906-0180870-2

12. Shikha Singh,Ravi Prakash, Gyan Prakash Singh. "Prevalence and Associated Risk Factors of Hypertension: A Cross-Sectional Study in Urban Varanasi." International journal of hypertension.vol. 2017. https://doi.org/10.1155/2017/5491838

13. Huang $\mathrm{Y}$, et al.Poor sleep quality, stress status, and sympathetic nervous system activation in nondipping hypertension; Blood Press Monit. 2011 Jun; 16(3):117123.

14. Boone JL, Stress and hypertension. Prim Care. 1991 Sep;18(3):623-49.

How to cite this article: Radhika P, Jose A. Evaluation and comparison of stress status between hypertensive and normotensive subjects. Int J Health Sci Res. 2021; 11(11):138144. DOI: https://doi.org/10.52403/ijhsr. 20211118 